\title{
Gene Expression of Aromatases, Steroid Receptor, GnRH and GTHs in the Brain during the Formation of Ovarian Cavity in Red Spotted Grouper, Epinephelus akaara
}

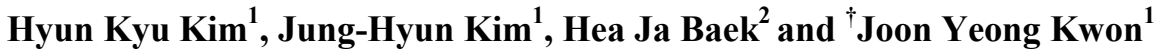 \\ ${ }^{1}$ Dept. of Aquatic Life Medical Science, Sunmoon University, Asan 31460, Korea \\ ${ }^{2}$ Dept. of Marine Biology, Pukyong National University, Busan 48513, Korea
}

\begin{abstract}
Red spotted grouper, Epinephelus akaara, is a popular aquaculture species and a protogynous hermaphrodite. Induction of artificial sex change at the time of primary sex differentiation is of interest but has not been successful due to the lack of necessary basic information. To find out the potential neuroendocrine influence on the primary sex differentiation, the expression of key genes in the brain was investigated during the formation of ovarian cavity. Expression of cyp 19alb, esr 1 , gnrhrl, $f_{s h}, \mathrm{lh}$ and $c g a$ in the brain was positively associated with the formation of ovarian cavity, showing gradual increase as the formation proceeds. However, the expression of gnrhl was suppressed during the early part of the ovarian cavity formation, signifying potential hypothalamic influence on the primary sex differentiation in this species.

Key words : Gonadal sex differentiation, Red spotted grouper, Protogynous, Hermaphroditism
\end{abstract}

\section{INTRODUCTION}

Red spotted grouper, Epinephelus akaara, is a popular aquaculture species in tropical and sub-tropical areas. This species is known to be a protogynous hermaphrodite that first differentiates into female and changes to male later (Tanaka et al., 1990; Okumura, 2001; Li et al., 2006; Li et al., 2007; Kim et al., 2015). The success of seed production in this species is largely dependent on the timely supply of male because natural sex change takes place long time after the primary sex differentiation at around 5 to 6 years old (Li et al., 2006; Li et al., 2007). Thus, induction of artificial sex change at the time of primary sex di- fferentiation could be a highly useful technique. To achieve this, however, further understanding on the process of primary sex differentiation is essential.

Classical concept of sexual differentiation in vertebrates suggests that the result of gonadal sex differentiation drives brain sex differentiation. It could be different particularly in the case of hermaphrodite fish. Serially sex changing teleosts demonstrate profound change in sexual behavior even before the gonadal trans-differentiation into a testis or an ovary indicating the influence of the brain (Grober \& Sunobe, 1996; Kobayashi et al., 2013). There are huge amounts of evidences that support the involvement of the brain in the process of sex change in pro-

\footnotetext{
Manuscript received October 26, 2016, Received in revised form November 27, 2016, Accepted December 20, 2016

${ }^{\dagger}$ Corresponding Author : Joon Yeong Kwon, Dept. of Aquatic Life Medical Science, Sunmoon University, Asan 31460, Korea. Tel: +82-41-530-2284, Fax: +82-41-530-2917, E-mail: jykwon@sunmoon.ac.kr

This is an Open Access article distributed under the terms of the Creative Commons Attribution Non-Commercial License (http:// creativecommons.org/licenses/by-nc/3.0) which permits unrestricted non-commercial use, distribution, and reproduction in any medium, provided the original work is properly cited.
} 
togynous hermaphrodite (reviewed by Baroiller et al., 1999). However, the influence of brain in the process of primary sex differentiation in hermaphrodite fish has not been sufficiently investigated yet.

It is well known that the primary sex differentiation is under the influence of sex steroid hormones in fishes (Yamazaki, 1983; Hunter \& Donaldson, 1983; Nakamura et al., 1998). Cytochrome P450 aromatase, a steroidogenic enzyme that converts androgens into estrogens, is also deeply associated with sex differentiation in fish (Kwon et al., 2001; Guiguen et al., 2009). This enzyme is encoded by two distinct genes (cyp19ala: P450aromA-ovary type; cyp 19alb: P450aromB-brain type) in various fish species (Kwon et al., 2001; Kwon \& Kim, 2013). The action of estrogen is mediated by estrogen receptor. However, the importance of estrogen receptor in the brain has not been properly explored so far with regard to gonadal sex differentiation in this species.

Several studies suggested that the importance of feedback regulation of gonadal steroids to orchestrate GnRHGTH release, which subsequently regulate sex steroid production during gametogenesis, serial sex change and natural sex reversal (Peter et al., 1991; Grober \& Sunobe, 1996; Goos et al., 1999; Zohar et al., 2010). As mentioned earlier, Baroiller et al. (1999) also suggested that the hypothalamic gonadotrophic axis may be needed to complete sex differentiation though not activate it.

The formation of the ovarian cavity is a characteristic landmark for the process of primary gonadal sex differrentiation in red spotted grouper (Kim et al., 2015). In many fish species, ovarian cavity are unequivocally discernible, allowing for the rapid identification of ovarian differentiation and detection any effects of estrogens or other sex steroids on gonadal differentiation (Dietrich \& Krieger, 2009).

To find out the potential neuroendocrine influence on the primary sex differentiation of protogynous herma- phrodites, we investigated the expression of two aromatase genes (cyp19ala and cyp19a1b), estrogen receptor alpha (esrl), GnRH and GnRH receptor genes (gnrh1 and gnrhrl) and three gonadotropin subunit genes (FSH $\beta f_{s} h$, LH $\beta$ lh and common glycoprotein alpha $c g a$ ) in the brain of red spotted grouper during the formation of ovarian cavity.

\section{MATERIALS AND METHODS}

\section{Fish and tissue sampling}

Red spotted grouper, E. akaara was obtained from Cheongsol aquaculture farm in Muan-gun, Jeonnam, Korea, and transported to a fish rearing facility in Sunmoon University. Fish were reared at $27 \pm 1{ }^{\circ} \mathrm{C}$ and $31 \pm 1 \%$ in indoor tanks. Photoperiod was maintained at 14 hours light : 10 hours dark (14L:10D). Fish were fed a commercial diet (40 to $80 \mathrm{DPH}$, days post-hatch: Ottohime, Japan; 80 to 130 DPH: Myungsun, Korea) ad libitum twice a day. Sampling was carried out every 5 days between 40 to $105 \mathrm{DPH}$ $(n=7-8$ at each sampling date). After that, fish were sampled additionally at $120(n=4)$ and 130 DPH $(n=3)$. These fish were anesthetized by 50 ppm benzocaine (Sigma, USA) and killed to remove whole brain including the pituitary. The brain of fish from 40 to $70 \mathrm{DPH}$ was removed together with cranium and surrounding tissues because the size of the brain was tiny. The brain of fish from 75 to $130 \mathrm{DPH}$ was removed only with the pituitary out of the head part.

2. Identification of esr1, gnrh1 and gnrhr1 in the brain of red spotted grouper

Sequences for esrl, gnrh and gnrhrl of red spotted grouper were not available in GenBank database since these genes have not been studied previously in this species. To identify these genes and obtain partial sequences, degenerate PCR was conducted using sequence 
information from the related species. Total RNA was extracted from the brain including the pituitary using TRIsure (Bioline, USA) and quantified using nanodrop1000 (Thermo, USA). This RNA $(1 \mu \mathrm{g})$ was reverse transcribed using TOPscritTM RT DryMIX (Enzynomics, Korea). The resultant cDNA was used as a template for subsequent degenerate PCR. Electrophoresis of PCR products were carried out in 1\% agarose gel. All primers for degenerate PCR were designed using the Primer 3 software (version 2.2.3) and listed in Table 1. The degenerate PCR was carried out using GoTaq ${ }^{\circledR}$ Green Master Mix (Promega, USA). The condition for degenerate PCR was as follows: initial denaturation at $95^{\circ} \mathrm{C}$ for $5 \mathrm{~min}$, 40 cycles of denaturation at $95^{\circ} \mathrm{C}$ for 15 seconds, annealing at $60{ }^{\circ} \mathrm{C}$ for 15 seconds and elongation at $72^{\circ} \mathrm{C}$ for $1 \mathrm{~min}$. PCR products were then sequenced by 3730xl DNA Analyzer (Applied biosystems, USA).

3. Expression of cyp19a1a, cyp19a1b, esr1, gnrh1, gnrhr1, fsh, Ih and cga in the brain

Extraction, quantification and reverse transcription of total RNAs were the same as described earlier in this study. Expression of cyp19ala, cyp19alb, esr1, gnrh1, gnrhrl, $f s h, l h$ and $c g a$ in the brain of red spotted grouper during the formation of ovarian cavity was investigated by quantitative real time -PCR (qRT-PCR) using the resultant cDNAs as templates. Primers for qRT-PCR were designed
Designer software (Bio-Rad, Hercules, CA, USA), and listed in Table 2. The qRT-PCRs were carried out using Topreal $^{\text {TM }}$ qPCR 2× PreMIX SYBR Green (Enzynomics, Korea) and CFX96 Touch $^{\mathrm{TM}}$ Real-Time PCR Detection System (Bio-Rad). Abundance level of each mRNA was normalized against the amount of $\beta$-actin mRNA. Relative abundance was determined using the comparative threshold cycle method, $2^{-} \Delta \mathrm{Ct}$, along with CFX Manager ${ }^{\mathrm{TM}}$ Software (Bio-Rad). Relative expression values of all samples were categorized and analyzed on the basis of day post-hatch and the status of ovarian cavity formation.

\section{Histology}

Fish were first fixed in $10 \%$ formalin for 12 hours. After removing the head and tail from the fixed fish, the remaining tissues (trunk part) were further fixed in $10 \%$ formalin again for another 12 hours. The fixed tissues were then dehydrated with ascending alcoholic series, cleared in xylene, and embedded in paraffin wax. Tissues were cut into a thickness of 5-8 $\mu \mathrm{m}$, stained with haematoxylin \& eosin. Tissue sections were observed under light microscope (DM500, Leica, Germany) to judge the status of ovarian cavity formation individually.

\section{Statistical analysis}

Data were presented as mean \pm SEM. Statistical differences of mRNA expression between different DPH was

Table 1. Primers used for degenerate PCR to identify red spotted grouper estrogen receptor alpha, GnRH1 and GnRH receptor 1 gene

\begin{tabular}{ccc}
\hline \hline Genes & & Primer sequence \\
\hline \multirow{2}{*}{ Estrogen receptor alpha } & Forward & 5'- CAGTGACATGTATCCCGAAGAG- 3' \\
& Reverse & 5'- CTCAGATGTTGCCGTCTCATAG- 3' \\
GnRH1 & Forward & 5'- GCCTCCTGCACAGAAGAAT- 3' \\
& Reverse & 5' - AATCCTTTGGTTCTGTAAATCTTGG- 3' \\
GnRH receptor 1 & Forward & 5'- GCAGTAACCTCGCCCTATTT- 3' \\
& Reverse & 5'-CTTCTGTCCTCTGATTGGCTAC- 3' \\
\hline
\end{tabular}

using the Primer 3 software (version 2.2.3) and Beacon 
Table 2. Primers used for quantitative real-time PCR to investigate the expression of P450aromA, P450aromB, estrogen receptor alpha, GnRH1, GnRH receptor 1, FSH $\beta$, LH $\beta$ and common glycoprotein $\alpha$

\begin{tabular}{|c|c|c|c|}
\hline $\begin{array}{c}\text { Genes } \\
\text { (Accession number) }\end{array}$ & & Primer sequence & Product length \\
\hline $\begin{array}{l}\text { Aromatase-a } \\
(\text { AY547354) }\end{array}$ & $\begin{array}{l}\text { Forward } \\
\text { Reverse }\end{array}$ & $\begin{array}{l}\text { 5'- ACGCCATAGAAAGTCTTGTAG - 3' } \\
\text { 5'- GCAGTGAAGTTGATGTTATCG - 3' }\end{array}$ & 79 \\
\hline $\begin{array}{l}\text { Aromatase-b } \\
(\text { AY547353.1) }\end{array}$ & $\begin{array}{l}\text { Forward } \\
\text { Reverse } \\
\text { Reverse }\end{array}$ & $\begin{array}{l}\text { 5'- GGAGGTCCTTCTGGAATGTAAAC - 3' } \\
\text { 5'- CCGACGTTCTGAGCAAAGATAA - 3' } \\
\text { 5'- GCCCATTTGACCACTTTGAC - 3' }\end{array}$ & 102 \\
\hline Estrogen receptor alpha & $\begin{array}{l}\text { Forward } \\
\text { Reverse }\end{array}$ & $\begin{array}{l}\text { 5'- CAACTCTGGTGCCTTCTCTTT - 3', } \\
\text { 5'- CCGACTGGCTGATATGATGTATG - 3' }\end{array}$ & 119 \\
\hline GnRH1 & $\begin{array}{l}\text { Forward } \\
\text { Reverse }\end{array}$ & $\begin{array}{l}\text { 5'- GACACACCGGGCAATATTCT - 3' } \\
\text { 5'- GTGATTCCTCCACACAACCA - 3' }\end{array}$ & 79 \\
\hline GnRH-receptor1 & $\begin{array}{l}\text { Forward } \\
\text { Reverse }\end{array}$ & $\begin{array}{l}\text { 5'- TGTGCTGGACTCCGTACTA - 3' } \\
\text { 5'- CAGGTTCCCAAACAGGAAGA - 3' }\end{array}$ & 110 \\
\hline $\begin{array}{c}\text { FSH } \beta \\
(\mathrm{KJ} 534537.1)\end{array}$ & $\begin{array}{l}\text { Forward } \\
\text { Reverse }\end{array}$ & $\begin{array}{l}\text { 5'- GACTGGACCTATGAGGTGAAAC - 3' } \\
\text { 5'-AAAGGACAGACAGCTGGATATG }\end{array}$ & 147 \\
\hline $\begin{array}{c}\mathrm{LH} \beta \\
(\mathrm{KJ} 534538.1)\end{array}$ & $\begin{array}{l}\text { Forward } \\
\text { Reverse }\end{array}$ & $\begin{array}{l}\text { 5' - GGGAGCCTCATCTTCCATTT - 3' - 3' } \\
\text { 5'- TTTGGACAGCCTTCCTTCTC - 3' }\end{array}$ & 108 \\
\hline $\begin{array}{c}\text { Common glycoprotein } \alpha \\
\text { (AY207430.1) }\end{array}$ & $\begin{array}{l}\text { Forward } \\
\text { Reverse }\end{array}$ & $\begin{array}{l}\text { 5’- CGATCCCGAAGAACATCATCTC } \\
\text { 5’- CTGTGTGGTTTCTCACCCTTAT - 3' - 3' }\end{array}$ & 96 \\
\hline $\begin{array}{c}\beta \text {-actin } \\
(\mathrm{HQ} 007251)\end{array}$ & $\begin{array}{l}\text { Forward } \\
\text { Reverse }\end{array}$ & $\begin{array}{l}\text { 5'- GACCTCACAGACTACCTCAT - 3' } \\
\text { 5'- GCTTCTCCTTGATGTCACG - 3' }\end{array}$ & 96 \\
\hline
\end{tabular}

analyzed by Mann-Whitney U-test $(P<0.05)$. Statistical differences of mRNA expression levels between different phases of ovarian cavity formation was analyzed by oneway ANOVA and Games-Howell range tests $(P<0.05)$. Statistical analyses were performed using SPSS version 18.0 .

\section{RESULTS \& DISCUSSION}

1. Identification of esr1, gnrh1 and gnrhr1 in the brain of red spotted grouper
Degenerate PCR successfully amplified a prominent band for each gene from the brain of red spotted grouper. The size of PCR product for esrl, gnrhl and gnrhrl were 523, 252 and 884 base pairs (bp), respectively (Table 3). The sequences of these fragments exhibited 96-99\% sequence identity to estrogen receptor alpha (accession number: GU721076) sequence, GnRH (accession number: HQ662335, HM030760) and GnRH-receptor1 (accession number: DQ536435) of other grouper species such as $E$. coioides, E. adscensionis, E. fasciatus. 
Hypothalamic Gonadotropic Influence on the Ovarian Cavity Formaion in Red Spotted Grouper

Table 3. Partial cDNA sequences of GnRH1, GnRH-receptor 1 and estrogen receptor alpha genes of red spotted grouper obtained in this study

\begin{tabular}{|c|c|}
\hline Genes (size) & Sequence $\left(5^{\prime} \rightarrow 3^{\prime}\right)$ \\
\hline \multirow{10}{*}{$\begin{array}{l}\text { Estrogen } \\
\text { receptor alpha } \\
\quad(523 \mathrm{bp})\end{array}$} & TCATACTGGACAGGACCGAAGGCAACTGTGTCGAAGGCATGGCTGAGATCTTTGACA \\
\hline & TGCTGCTGGCCACTGCCTCCCGCTTCCGCTTGCTCAAACTCAAACCCGAGGAGTTTG \\
\hline & TCTGTCTCAAAGCCATCATCTTGCTCAACTCTGGTGCCTTCTCTTTCTGCACCGGCAC \\
\hline & AATGGAGCCCCTCCATGACACCACAGCGGTGCAGAACATGCTTGACACCATCACAG \\
\hline & ATGCTCTCATACATCATATCAGCCAGTCGGGATGCTCGGTTCAGCAGCAGTCGAGAC \\
\hline & GGCAGGCCCAGCTGCTGCTTCTGCTCTCACACATCAGGCACATGAGCAACAAAGGC \\
\hline & ATGGAGCATCTCTACAGCATGAAGTGCAAGAACAAAGTGCCTCTGTACGACCTGCTC \\
\hline & CTGGAGATGCTGGATGCTCACCGCATCCAACGCCCTGACAAACCAGGTCAGACCTG \\
\hline & GTCCCAGGCTGATGGGGAGCCTCCCTCCAGCACCAGCAGCAGCGGTGGTTCCTCTT \\
\hline & CTTCAGCTGGCTC \\
\hline \multirow{5}{*}{$\begin{array}{l}\text { GnRH1 } \\
(252 \mathrm{bp})\end{array}$} & TGCCTCCTGCACAGAAGAATGGCTGCAAAATCCTTGGCACTGTGTCTGCTGCTTGTG \\
\hline & GGAGCAATGTTGCCACAGGGCCACTGTCAGCACTGGTCATATGGGCTGAGCCCGGG \\
\hline & AGGGAAGAGGGATCTGGACAGCCTCTCGGACACACCGGGCAATATTCTTGAGGGGT \\
\hline & TTCCACATGTGGACACACCCTGCAGTGTTTTTGGTTGTGTGGAGGAATCACCTTTTG \\
\hline & CCAAGATTTACAGAACCAAAGGATTA \\
\hline \multirow{16}{*}{$\begin{array}{c}\text { GnRH-receptor } 1 \\
\text { (884 bp) }\end{array}$} & GTCTGGCGTCTCACCTGCGGCCGTTAATGCTGAGCCTGGCGTCAGCTGACCTGATGA \\
\hline & TGACATTTGTGGTGATGCCTCTGGATGCCGTGTGGAACGTTACAGTGCAGTGGTATG \\
\hline & GAGGAGACGTGCTCTGTAAGCTGCTCTGCTTCCTGAAGCTGTTCGCCATGCACGCCT \\
\hline & CCGCCTTCATCCTTGTTGTCATCAGCCTCGATCGCCAGCACGCCATCCTGCACCCGCT \\
\hline & GGACGCCCTGAACGCACACCGCAGGAACCGACGCATGCTGCTGCTGGCCTGGAGCC \\
\hline & TCAGCCTGGTGCTTGCATCACCACAGCTGTTTATCTTCCGGACGATCAGGGTGGAGG \\
\hline & CCGTGGACTTCACTCAGTGTGCCACTCACGGCAGCTTCAGCCACCGCTGGCAGGAA \\
\hline & ACTGTTTACAACATGTTTCACTTCATCACGCTGTACGTCGTCCCCCTGCTGGTGATGA \\
\hline & GCTGCTGCTACAGCCGCATCCTGCTGCACATCCACCTGCAGCACCTGAGAGACAAA \\
\hline & GCAGGTGAGTCGTACCTGCGTCGCAGCGGCACTGACATCATCCCAAAGGCTCGCATG \\
\hline & AAGACTCTGAAGATGACGGTGGTCATCGTGCTGTCCTTTGTGGTGTGCTGGACTCCG \\
\hline & TACTACCTGCTGGGGATTTGGTACTGGTTCCAGCCCGACATGCTGCGCGTCACACCT \\
\hline & GAGTACGTACACCACGCCCTCTTCCTGTTTGGGAACCTGAACACCTGCTGCGACCCC \\
\hline & GTCATCTACGGCTTCTACACGCCATCCTTCAGGGCCGACCTCGCCGCCTGCTGCCGC \\
\hline & AGGACGAAGAGCGACGCTTCACTGCGATCTCCGGACCGACTGTCTGCCAGGCAGGA \\
\hline & TCCTCACAGCGCGGAGCATGAGGCGGACCCC \\
\hline
\end{tabular}

2. Aromatase and estrogen receptor genes in the brain during the formation of ovarian cavity
Based on the gonadal histology, the major period of ovarian cavity formation was found to be 65 to $105 \mathrm{DPH}$ 
in this species. All genes investigated in this study were detectable in the brain earlier than this period (40 to 60 DPH) but not high enough to compare with the expression levels during the ovarian cavity formation.

P450aromA mRNA (cyp19ala) in the brain significantly increased at 70 and $90 \mathrm{DPH}$ from the respective previous sampling date (Fig. 1). The levels tended to increase as the formation of ovarian cavity proceed but this increase was not statistically significant $(P>0.05)$. P450aromB mRNA (cyp19a1b) increased significantly from $75 \mathrm{DPH}$ and remained high during the rest of period investigated. As the formation of ovarian cavity proceed, the level of
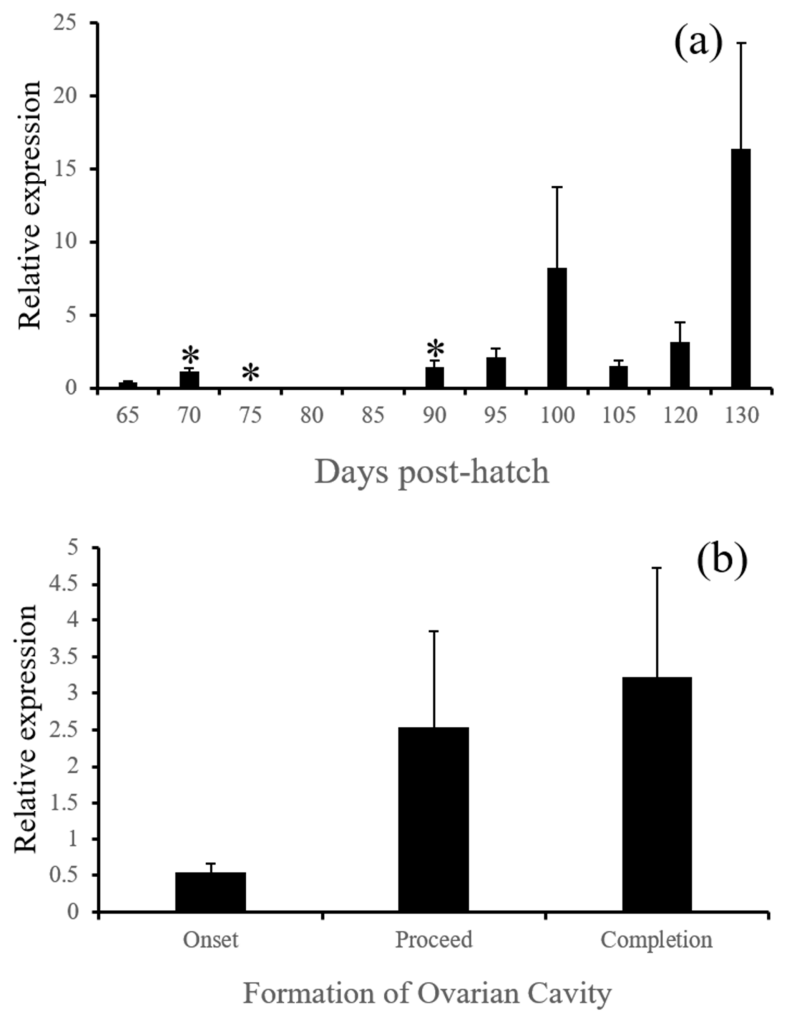

Fig. 1. Expression of P450aromA mRNA (cyp19a1a) in the brain at different days post-hatch (a) and at differrent phases of ovarian cavity formation (three phases: onset, proceed and completion) (b). Each bar represents the mean \pm SEM. * indicates significant differrence from the respective previous DPH $(P<0.05)$. Different letters on top of each bar indicate significant difference $(P<0.05)$. cyp19a1b expression increased significantly (Fig. 2, $P<$ 0.05 ). Our findings are in agreement with previous studies for other fish species where cyp19ala was contributable to gonadal sex differentiation (Kwon et al., 2001; Patil \& Gunasekera, 2008; Guiguen et al., 2009) wherase cyp$19 a 1 b$ was highly expressed in the brain and might cause the brain sex differentiation (Vizziano-Cantonnet et al., 2011). However, highly expressed cyp19alb in the brain is not likely to be the cause of the ovarian cavity formation since it was low at the onset of the formation.

Estrogen receptor alpha mRNA (esrl) in the brain of red spotted grouper significantly increased from $90 \mathrm{DPH}$ and remained high during the rest of period investigated. As
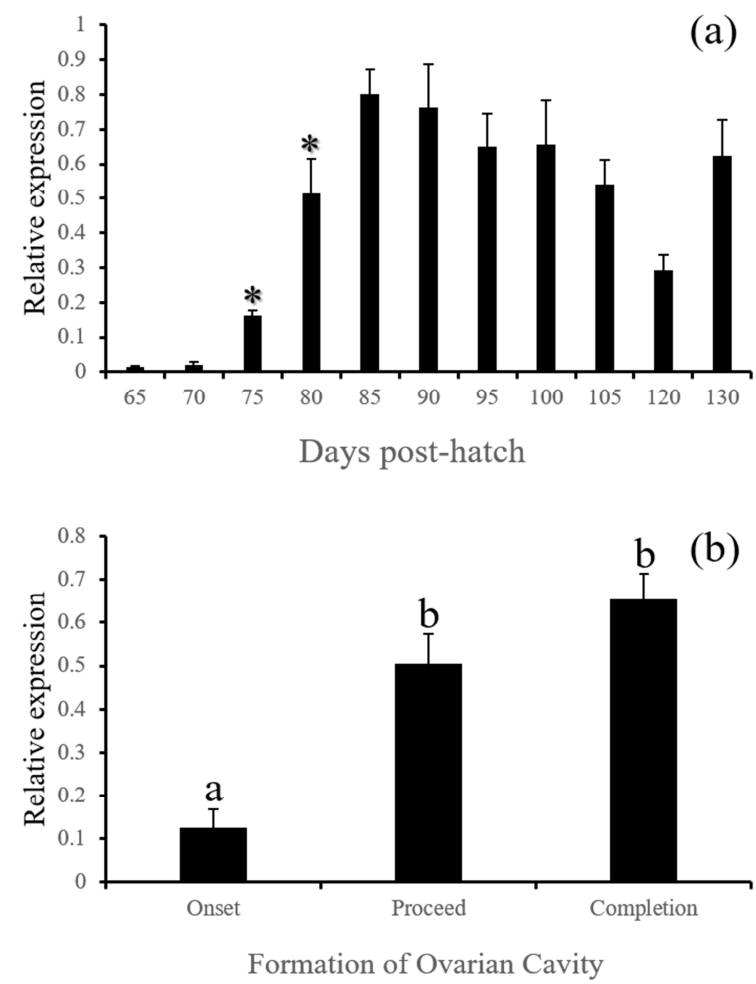

Fig. 2. Expression of P450aromB mRNA (cyp19a1b) in the brain at different days post-hatch (a) and at differrent phases of ovarian cavity formation (three phases: onset, proceed and completion) (b). Each bar represents the mean \pm SEM. * indicates significant differrence from the respective previous DPH $(P<0.05)$. Different letters on top of each bar indicate significant difference $(P<0.05)$. 

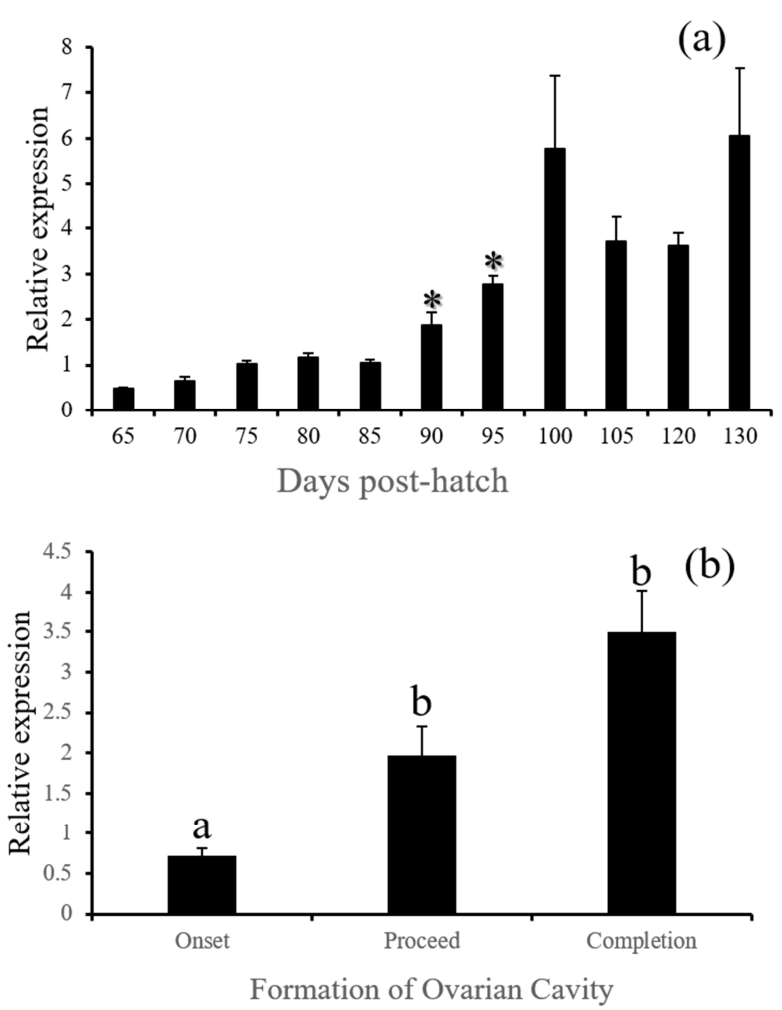

Fig. 3. Expression of estrogen receptor alpha mRNA (esrl) in the brain at different days post-hatch (a) and at different phases of ovarian cavity formation (three phases: onset, proceed and completion) (b). Each bar represents the mean \pm SEM. * indicates significant differrence from the respective previous DPH $(P<0.05)$. Different letters on top of each bar indicate significant differrence $(P<0.05)$.

the formation of ovarian cavity proceed, the level of esr 1 expression increased significantly (Fig. 3, $P<0.05$ ). Brain aromatase activity is correlated to sex steroid levels, and the high expression of cyp 19alb is associated to an autoregulatory loop through which estrogens and aromatizable androgens up-regulate aromatase expression. This process requires estrogen receptor binding on an estrogen response element located on the cyp19a1b promoter (Diotel et al., 2010). These together suggest active production of estrogens and auto-regulation in the brain at the time of ovarian cavity formation. In supporting of this, Nakamura
\& Nagahama (1985) have noticed the presence of steroid producing cells at the beginning of ovarian cavity formation in a fish species.

3. Hypothalamic gonadotropic changes during the formation of ovarian cavity

gnrh - GnRH mRNA in the brain significantly increased at $70 \mathrm{DPH}$ and remain suppressed until $90 \mathrm{DPH}$ (Fig. 4, $P<0.05)$. Since then, it recovered back to the level before 70 DPH. However, the levels did not show any differences with regard to the formation of ovarian cavity $(P>0.05)$. In fish including red spotted species in this study, the strong
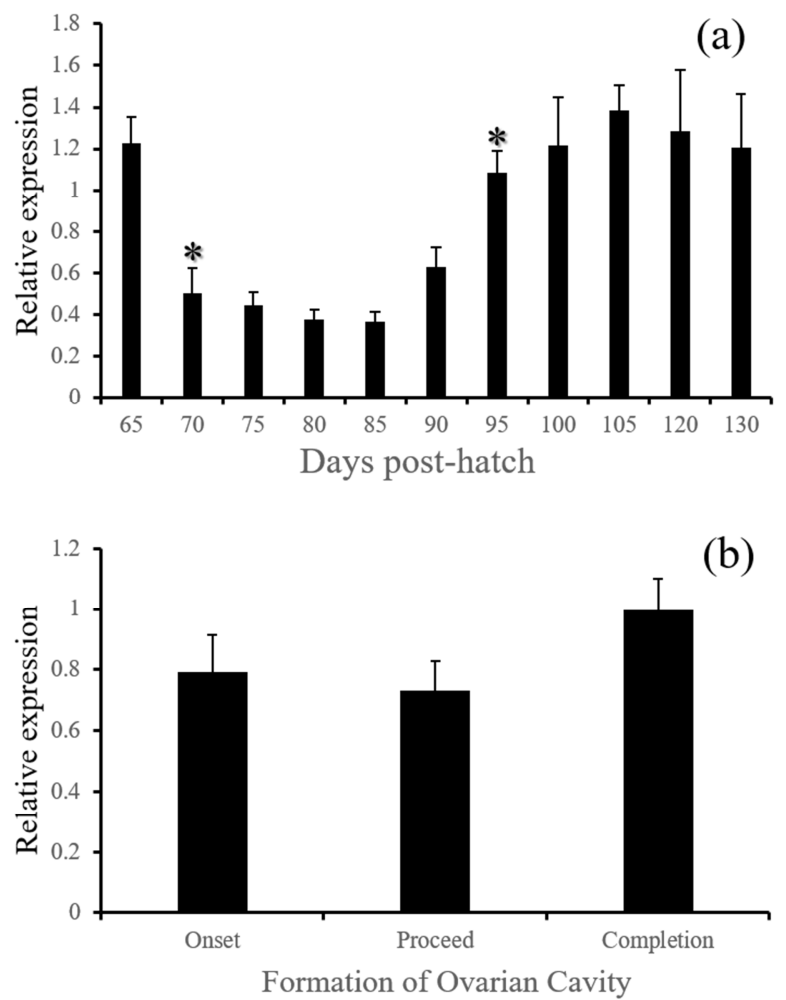

Fig. 4. Expression of GnRH1 mRNA (gnrh1) in the brain at different days post-hatch (a) and at different phases of ovarian cavity formation (three phases: onset, proceed and completion) (b). Each bar represents the mean \pm SEM. * indicates significant difference from the respective previous DPH $(P<0.05)$. Different letters on top of each bar indicate significant difference $(P<0.05)$. 
expression of gnrh appear to be in favor of testicular differentiation rather than ovarian differentiation. Nile tilapia showed clear differential temporal patterns of $\mathrm{GnRH}$ localization and expression between genetic male and genetic female larva (Swapna et al., 2008). In European sea bass, the expression of GnRH gene was signicantly higher in male-dominant population than female-dominant population (Moles et al., 2007). Suppressed expression of gnrh in this study are consistent with these findings, signifying potential hypothalamic influence on the primary sex differentiation in this species.
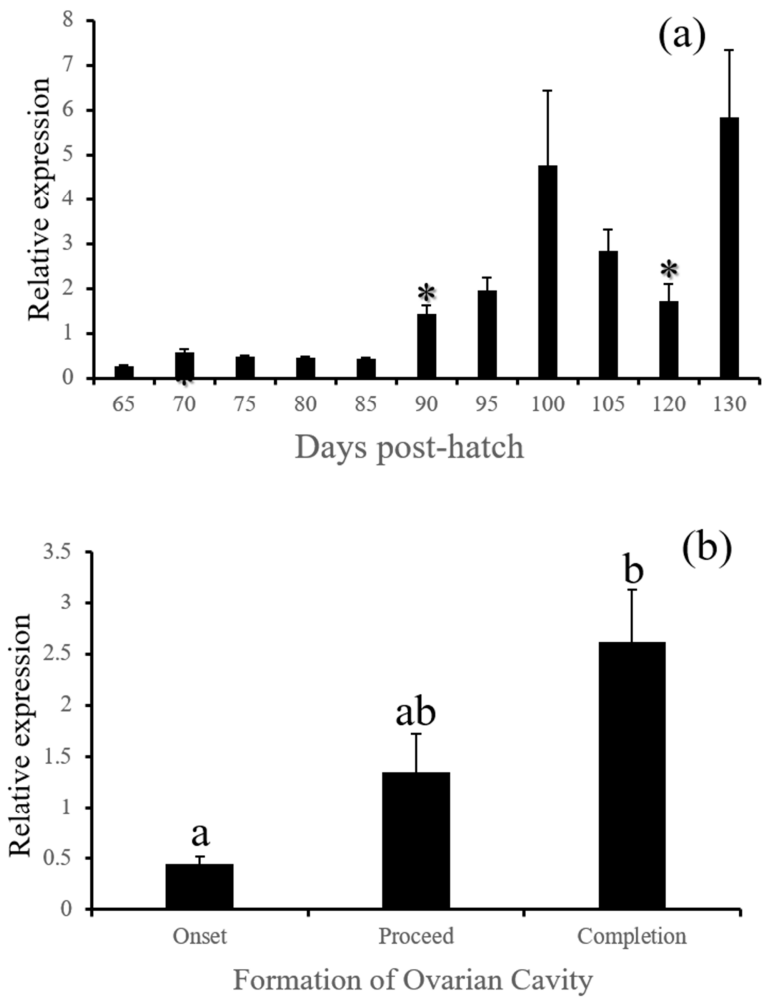

Fig. 5. Expression of GnRH receptor 1 mRNA (gnrhrl) in the brain at different days post-hatch (a) and at different phases of ovarian cavity formation (three phases: onset, proceed and completion) (b). Each bar represents the mean \pm SEM. indicates significant differrence from the respective previous DPH $(P<0.05)$. Different letters on top of each bar indicate significant difference $(P<0.05)$. gnrhr1 - GnRH-receptor 1 mRNA in the brain was started to be actively expressed from $90 \mathrm{DPH}$ and remained high since then. This increased level seems associated with the formation of ovarian cavity as the level was significantly higher at the phase of completion than the level at the onset (Fig. 5, $P<0.05$ ).

$f_{s} h, l h$ and $c g a$ - These three GtH subunit genes in the brain were started to be actively expressed from 85 (for $l h$ and $c g a$ ) or $90 \mathrm{DPH}$ (for $f_{s h}$ ). Expression of these genes were associated with the formation of ovarian cavity, showing significantly higher levels at the phase of completion (Fig. 6, 7 and 8, $P<0.05$ ).
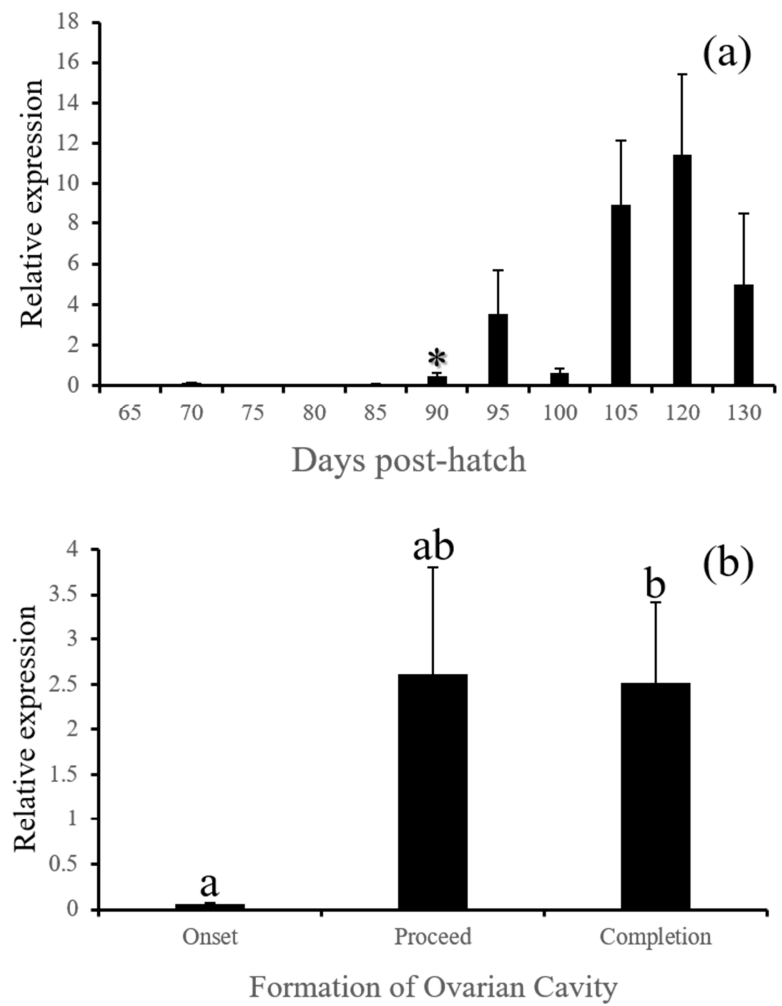

Fig. 6. Expression of FSH $\beta$ mRNA $(f s h)$ in the brain at different days post-hatch (a) and at different phases of ovarian cavity formation (three phases: onset, proceed and completion) (b). Each bar represents the mean \pm SEM. * indicates significant difference from the respective previous DPH $(P<$ 0.05). Different letters on top of each bar indicate significant difference $(P<0.05)$. 

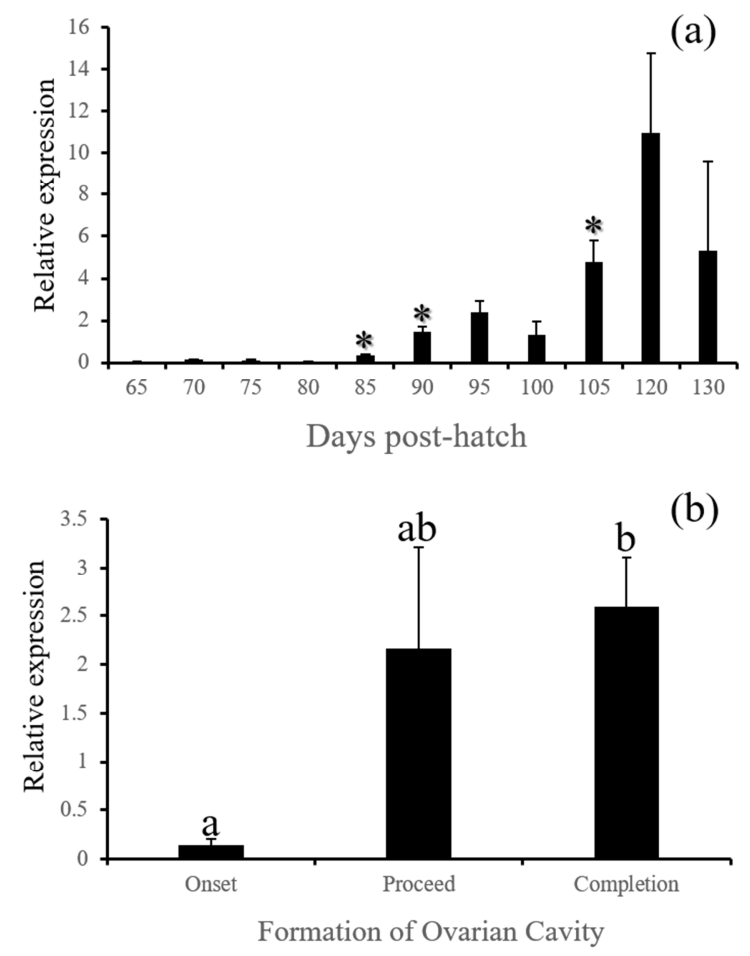

Fig. 7. Expression of LHß mRNA $(l h)$ in the brain at different days post-hatch (a) and at different phases of ovarian cavity formation (three phases: onset, proceed and completion) (b). Each bar represents the mean \pm SEM. * indicates significant difference from the respective previous DPH $(P<$ 0.05). Different letters on top of each bar indicate significant difference $(P<0.05)$.

GnRH receptor in the pituitary relays hypothalamic signals to gonadotropic cells to induce the production of $\mathrm{GtH}$. Similar expression patterns of ghrhrl, fsh, lh and cga observed in this study is well agreed to this flow of hormonal signals in animals. Expressions of all these genes were closely associated with the formation of ovarian cavity although none of these were initiating factors for the sex differentiation. Baroiller et al. (1999) suggested that the hypothalamic gonadotrophic axis may be needed to complete sex differentiation but not activate it. The hypothalamic gonadotropic influence on fish sex is particularly obvious in hermaphrodite fish. In a protogynous species the bluehead wrasse, Thalassoma bifasciatum,
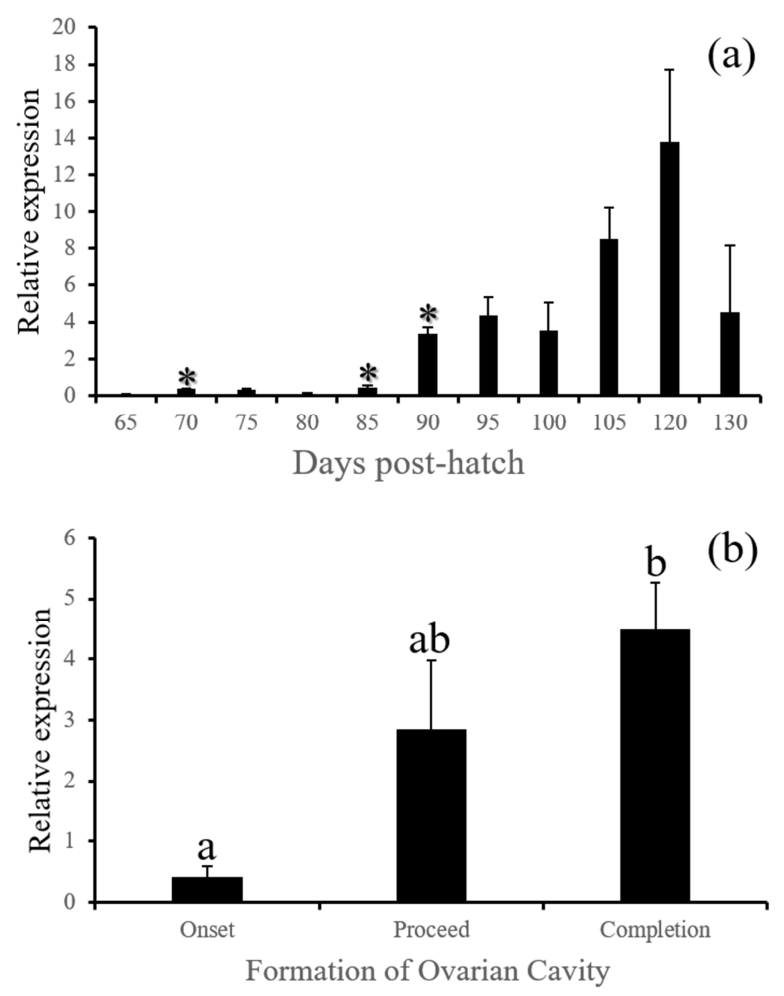

Fig. 8. Expression of common glycoprotein $\alpha$ mRNA (cga) in the brain at different days post-hatch (a) and at different phases of ovarian cavity for mation (three phases: onset, proceed and completion) (b). Each bar represents the mean \pm SEM. * indicates significant difference from the respective previous DPH $(P<0.05)$. Different letters on top of each bar indicate significant difference $(P<0.05)$.

injection of females with human chorionic gonadotropin (hCG) induced in all cases a significant percentage of female-to-male sex inversions, demonstrating that a short rise in gonadotropic secretion will trigger sex inversion without the need for high sustained secretions (Koulish and Kramer, 1989). Red spotted grouper is a protogynous like the bluehead wrasse, and showed siginificant decrease of gnrh and increase of gonadotropic factors such as gnrhrl, fsh, lh and cga during the formation of ovarian cavity, suggesting that the primary sex differentiation of this species might be sensitive to artificial treatment with GnRH or GtH. 
In conclusion, highly expressed cyp19alb in the brain is not likely to be the cause of the ovarian cavity formation since it was low at the onset of the formation. Active production of estrogens and auto-regulation may take place in the brain at the time of ovarian cavity formation in this species. The hypothalamic gonadotropic influence on fish sex seems obvious in hermaphrodite fish. Red spotted grouper is a protogynous, and showed siginificant decrease of gnrh and increase of gonadotropic factors such as gnrhrl, $f_{s h}$, lh and cga during the formation of ovarian cavity, suggesting that the primary sex differentiation of this species might be sensitive to artificial treatment with GnRH or GtH. Further studies should prove this by means of in vivo experiment.

\section{ACKNOWLEDGEMENTS}

This research was supported by the Korean Ministry of Agriculture, Food and Rural Affairs (MAFRA), the Korean Ministry of Oceans and Fisheries (MOF), the Korean Rural Development Administration (RDA), and Korea Forest Service (KFS) (Grant number: 213004-04-04-SB$620)$.

\section{REFERENCES}

Baroiller JF, Guiguen Y, Fostier A (1999) Endocrine and environmental aspects of sex differentiation in fish. Cell Mol Life Sci 55:910-931.

Dietrich DR, Krieger HO (2009) Histological Analysis of Endocrine Disruptive Effects in Small Laboratory Fish. John Wiley \& Sons, Inc., New Jersey, pp. 19-51.

Diotel N, Le Page Y, Mouriec K, Tong SK, Pellegrini E, Vaillant C, Anglade I, Brion F, Pakdel F, Chung BC, Kah O (2010) Aromatase in the brain of teleost fish: expression, regulation and putative functions. Front Neuroendocrinol 31:172-192.

Grober MS, Sunobe T (1996) Serial adult sex change involves rapid and reversible changes in forebrain neurochemistry. NeuroReport 7:2945-2949.

Goos HJ, Senthilkumaran B, Joy KP (1999) Neuroendocrine integrative mechanisms in the control of gonadotropin secretion in teleosts. Narousa New Delhi 113-136.

Guiguen Y, Fostier A, Piferre F, Chang C-F (2009) Ovarian aromatase and estrogens: A pivotal role for gonadal sex differentiation and sex change in fish. Gen Comp Endocrinol 165:352-366.

Hunter GA, Donaldson EM (1983) Hormonal sex control and its application to fish culture. In: W.S. Hoar, D.J. Randall, and EM Donaldson (Editors), Fish Physiol, Vol. 9B. Academic Press, New York, pp. 223-303.

Kobayashi Y, Murata R, Nakamura M (2013) Physiological and endocrinological mechanisms of sex change in the grouper. Nova Biomedical 13:221-233.

Kim HK, Kim JH, Kim WS, Baek HJ, Kwon JY (2015) Early gonadal differentiation of the protogynous red spotted grouper, Epinephelus akaara. Dev Reprod 19: 209-215.

Koulish S, Kramer CR (1989) Human chorionic gonadotropin (hCG) induces gonadal reversal in a protogynous fish, the bluehead wrasse, Thalassoma bifasciatum (Teleostei, Labridae). J Exp Zool 252:156-168.

Kwon JY, McAndrew BJ, Penman DJ (2001) Cloning of brain aromatase gene and expression of brain and ovarian aromatase genes during sexual differentiation in genetic male and female Nile tilapia Oreochromis niloticus. Mol Reprod Develop 59:359-370.

Kwon JY, Kim J (2013) Differential expression of two distinct aromatase genes (cyp19ala and cyp19a1b) during vitellogenesis and gestation in the viviparous black rockfish Sebastes schlegelii. Ani Cells Sys 17: $88-98$.

Li GL, Liu XC, Lin HR (2006) Effects of aromatizable and nonaromatizable androgens on the sex inversion of red- 
spotted grouper (Epinephelus akaara) Fish Physiol Biochem 32:25-33.

Li GL, Liu XC, Lin HR (2007) Seasonal changes of serum sex steroids concentration and aromatase activity of gonad and brain in red-spotted grouper (Epinephelus akaara). Ani Reprod Sci 99:156-166.

Moles G, Carrillo M, Mananos E, Mylonas CC, Zanuy S (2007) Temporal profile of brain and pituitary GnRHs, GnRH-R and gonadotropin mRNA expression and content during early development in European sea bass (Dicentrachus labrax L). Gen Comp Endocrinol 150: 75-86.

Nakamura M, Nagahama Y (1985) Steroid producing cells during ovarian differentiation of the tilapia, Sarotherodon niloticus. Dev Growth \& Different 27:701708.

Nakamura M, Kobayashi T, Chang XT, Nagahama Y (1998) Gonadal sex differentiation in teleost fish. J Exp Zool 281:362-372.

Okumura S (2001) Evidence of sex reversal towards both directions in reared red spotted grouper Epinephelus akaara. Fish Sci 67: 535-537.

Peter RE, Trudeau VL, Sloley BD (1991) Brain regulation of reproduction in teleosts. Bull Inst Zool Acad Sin 16:89-118.

Patil JG, Gunasekera RM (2008) Tissue and sexually dimorphic expression of ovarian and brain aromatase mRNA in the Japanese medaka (Oryzias latipes): implications for their preferential roles in ovarian and neural differentiation and development. Gen Comp Endocrinol 158:131-137.

Swapna I, Sudhakumari CC, Sakai F, Sreenivasulu G, Kobayashi T, Kagawa H, Nagahama Y (2008) Seabream GnRH immunoreactivity in brain and pituitary of XX and XY Nile tilapia Oreochromis niloticus during early development. J Exp Zool A 309:419-442.

Tanaka H, Hirose K, Nogami K, Hattori K, Ishibashi N (1990) Sexual maturation and sex reversal in red spotted grouper, Epinephelus akaara. Bull Natl Res Inst Aquacult 17: 1-15.

Vizziano-Cantonnet D, Anglade I, Pellegrini E, Gueguen MM, Fostier A, Guiguen Y, Kah O (2011) Sexual dimorphism in the brain aromatase expression and activity, and in the central expression of other steroidogenic enzymes during the period of sex differentiation in monosex rainbow trout populations. Gen Comp Endocrinol 170:346-355.

Yamazaki F (1983) Sex control and manipulation in fish. Aquacult 33:329-354.

Zohar Y, Munoz-Cueto JA, Elizur A, Kah O (2010) Neuroendocrinology of reproduction in teleost fish. Gen Comp Endocrinol 165:438-455. 